\title{
Pengaruh Budaya Organisasi dan Lingkungan Kerja Terhadap Kinerja Karyawan PT. BPR Desa Sangeh Abiansemal Badung
}

\author{
Ni Putu Sintia Juliani ${ }^{1}$ \\ Gusti Alit Suputra ${ }^{2}$ \\ ${ }^{1,2}$ Fakultas Ekonomi Bisnis dan Pariwisata Universitas Hindu Indonesia \\ Email : sintyajuliani61@gmail.com
}

\begin{tabular}{|l|l|l|}
\hline Diterima: 9 Desember & Direvisi: 15 Desember & Disetujui: 27 Desember 2020 \\
\hline
\end{tabular}

\begin{abstract}
Human resources are the most important assets of an organization because they are one of the assets that have a vital role in moving the organization to achieve its goals. The purpose of this study was to examine the influence of organizational culture and work environment on employee performance at PT. BPR Desa Sangeh Abiansemal Badung partially and simultaneously. The population in this study were all employees of PT. BPR Desa Sangeh Abiansemal Badung, amounting to 34 people, sampling using the census method, namely all employees of PT. BPR Desa Sangeh Abiansemal Badung, amounting to 34 people. Data collection using a questionnaire. The data analysis technique used is multiple linear regression analysis. The results of data analysis show that organizational culture and work environment have a positive and significant effect partially and simultaneously on the performance of employees of PT. BPR Sangeh Village. Suggestions that can be given are to improve organizational culture and work environment conditions so that employee performance increases.
\end{abstract}

Keywords: organizational culture, work environment, employee performance

\begin{abstract}
ABSTRAK
Sumber daya manusia adalah aset terpenting suatu organisasi karena merupakan salah satu modal yang memiliki peranan vital dalam menggerakkan organisasi untuk mencapai sasaran. Tujuan penelitian ini adalah untuk menguji pengaruh budaya organisasi dan lingkungan kerja terhadap kinerja karyawan pada PT. BPR Desa Sangeh Abiansemal Badung secara parsial dan simultan. Populasi dalam penelitian ini adalah seluruh karyawan PT. BPR Desa Sangeh Abiansemal Badung yang berjumlah 34 orang, pengambilan sampel menggunakan metode sensus yaitu seluruh karyawan PT. BPR Desa Sangeh Abiansemal Badung yang berjumlah 34 orang. Pengumpulan data menggunakan kuesioner. Teknik analisis data yang digunakan adalah analisis regresi linier berganda. Hasil analisis data menunjukkan budaya organisasi dan lingkungan kerja berpengaruh positif dan signifikan secara parsial dan simultan terhadap kinerja karyawan PT. BPR Desa Sangeh. Saran yang dapat diberikan adalah agar meningkatkan budaya organisasi dan kondisi lingkungan kerja agar kinerja karyawan meningkat.
\end{abstract}

Kata kunci : budaya organisasi, lingkungan kerja, kinerja karyawan.

\section{Pendahuluan}


Keberhasilan suatu organisasi untuk mencapai tujuan atau sasaran yang telah ditetapkan tentu sangat bergantung kepada kualitas sumber daya manusia (SDM) yang dimiliki, tidak terkecuali pada sektor perbankan di mana SDM adalah satu-satunya faktor yang mampu menggerakkan fungsi atau sumber daya lainnya dalam suatu organisasi. Tercapainya tujuan perusahaan salah satunya sangat bergantung pada baik buruknya kinerja karyawan sehingga sangat penting bagi suatu organisasi untuk senantiasa memperhatikan kinerja yang dimiliki oleh karyawannya serta memahami faktor-faktor apa saja yang dapat mempengaruhi kinerja karyawan.

Kinerja menunjukkan pencapaian seorang karyawan atas hasil pekerjaan yang dapat dinilai dalam bentuk kuantitatif maupun kualitatif sesuai dengan tugas dan tanggung jawab (Mangkunegara, 2005: 67). Simamora (2015:93) mengemukakan bahwa kinerja pegawai adalah tingkatan di mana para pegawai mencapai persyaratan-persyaratan pegawaian. Tinggi rendahnya kinerja dapat diukur dari hasil yang dicapai oleh seorang pegawai.

Usaha untuk meningkatkan kinerja karyawan, diantaranya adalah memperhatikan budaya organisasi pada perusahaan. Agar tercapainya hasil yang diharapkan, maka pihak perusahaan dalam hal ini harus mampu menerapkan budaya organisasi yang baik serta mampu mengelola konflik yang ada. (Cahyono. 2012) berpendapat peningkatan kinerja sulit akantercapai apabila terjadi budaya yang bertentangan antara anggota di dalam organisasi di mana para anggota bertahan dengan pendapat masing-masing.

Robbins (2010) menjelaskan bahwa budaya organisasi mempengaruhi cara-cara anggota organisasi dalam bertindak sebagai akibat dari adanya nilai, tradisi, mapun cara bekerja yang dianut. Pratiwi (2012:70) dalam penelitiannya menjelaskan bahwa budaya organisasi mampu meningkatkan kinerja karyawan. Faktor berikutnya yang dapat mempengaruhi kinerja karyawan adalah lingkungan kerja, karena bersinggungan langsung dengan karyawan selama melaksanakan pekerjaan.

Lingkungan di mana karyawan melaksanakan pekerjaan disebut sebagai lingkungan kerja (Budianto dan Katini dalam Mardiana, 2015:104). Karyawan akan dapat bekerja dengan optimal ketika didukung lingkungan kerja yang kondusif. Menurut Rahmawanti dkk dalam Sedarmayanti (2014:3) menyatakan lingkungan kerja tidak hanya mencakup peralatan maupun bahan pekerjaan, namun lebih luas lagi mencakup metode kerja dan pengaturan kerja untuk individu maupun kelompok. Hasil penelitian oleh Ajala (2012) membuktikan bahwa kinerja karyawan dipengaruhi oleh lingkungan kerja.

Studi penelitian ini dilaksanakan pada PT. BPR Desa Sangeh. PT. BPR Desa Sangeh 
merupakan sebuah lembaga keuangan yang berlokasi di Jl. Raya Sangeh, Kec. Abiansemal, Kab. Badung, Bali. BPR ini mengupayakan agar karyawan yang bekerja dalam perusahaan ini memiliki kinerja yang baik. Namun dalam kenyataanya karyawan belum memberikan kinerja yang baik kepada perusahaan. Kondisi ini dikhawatirkan akan dapat menyebabkan kinerja karyawan belum optimal. Tujuan penelitian ini adalah (1) untuk mengetahui pengaruh budaya organisasi secara parsial terhadap kinerja karyawan, (2) untuk mengetahui pengaruh lingkungan kerja secara parsial terhadap kinerja karyawan, dan (3) untuk mengetahui pengaruh budaya organisasi dan lingkungan kerja secara simultan terhadap kinerja karyawan pada PT. BPR Desa Sangeh Abiansemal Badung.

\section{Telaah Literatur Dan Hipotesis}

\section{Kinerja Karyawan}

Lawler \& Porter (dalam Sutrisno, 2014:150) mendefinisikan kinerja adalah "successful role achievement" (keberhasilan pencapaian) yang diperoleh seseorang dari perbuatanperbuatannya dalam menjalankan pekerjaannya. Kinerja Merupakan hasil pelaksanan suatu pekerjaan baik berfisat fisik maupun non fisik ( Hadari Nawawi, 2005). Hal ini juga didukung dengan pendapat Cokroaminoto (2007) bahwa kemampuan karyawan memenuhi tuntutan tugas dan tanggung jawab adalah cerminan kinerja karyawan.

\section{Budaya Organisasi}

Ciri khas suatu organisasi seringkali ditentukan oleh nilai yang telah lama berkembang dan berlaku di dalam organisasi tersebut yang menajdikannya sebagai suatu budaya organisasi (Priansa dan Garnida, 2013:77), sedangkan menurut Robbins dan Judge (2011) dikutip Priansa dan Garnida (2013:77) menyatakan setiap organisasi dibedakan oleh adanya budaya organisasi yang unik dengan prinsip berbagi nilai yang diterapkan atau dipraktekkan oleh anggota organisasi.

\section{Lingkungan Kerja}

Fasilitas-fasilitas kerja seperti penerangan di tempat kerja, tersedianya pendingin udara dan lainnya yang ada di sekitar tempat karyawan bekerja dan dapat menunjang kinerja karyawan disebut sebagai lingkungan kerja (Nitisemito dalam Nuraini, 2013). Segala sesuatu yang dapat mempengaruhi karyawan dalam bekerja dan menjalankan tugas dapat dikatakan sebagai lingkungan kerja yang antara lain meliputi temperatur udara, penerangan, kebersihan tempat kerja, dan ketersediaan perlatan kerja (Isyandi, 2009).

\section{Hipotesis.}

Berdasarkan kajian teoritis dan empiris yang telah dilakukan, mipotesis yang 
diajukan dalam penelitian ini adalah :

$\mathrm{H}_{1}$ : Diduga budaya organisasi secara parsial berpengaruh positif dan signifikan terhadap kinerja karyawan PT. BPR Desa Sangeh Abiansemal Badung.

$\mathrm{H}_{2}$ : Diduga lingkungan kerja secara parsial berpengaruh positif dan signifikan terhadap kinerja karyawan PT. BPR Desa Sangeh Abiansemal Badung.

$\mathrm{H}_{3}$ : Diduga budaya organisasi dan lingkungan kerja secara simultan berpengaruh positif dan signifikan terhadap kinerja karyawan PT. BPR Desa Sangeh Abiansemal Badung.

\section{METODE PENELITIAN}

Berdasarkan tujuan penelitian yang telah di kemukakan sebelumnya ,maka variabel - variabel yang dianalisis dalam penelitian ini adalah : budaya organisasi $\left(\mathrm{X}_{1}\right)$, dan lingkungan kerja $\left(\mathrm{X}_{2}\right)$ sebagai variabel bebas sedangkan kinerja $(\mathrm{Y})$ sebagai variabel terikat. Untuk lebih jelasnya dapat digambarkan sebagai berikut:

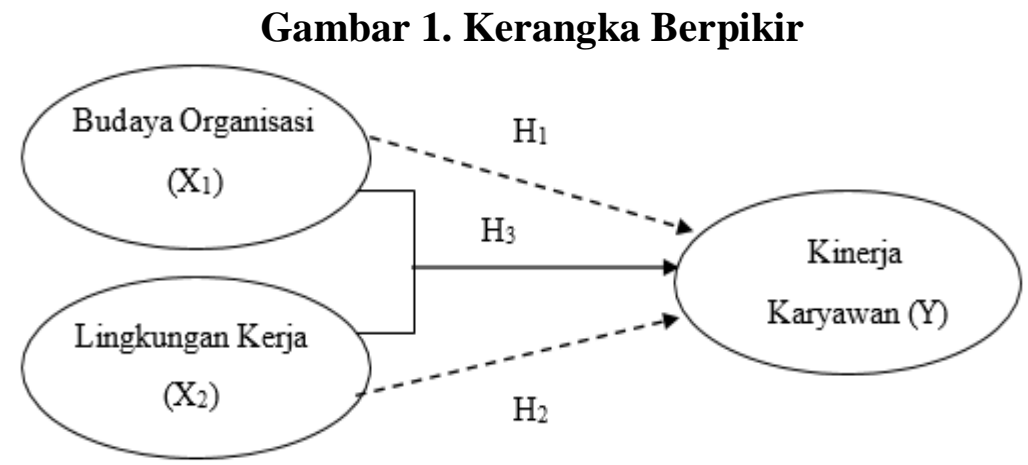

Populasi dalam penelitian ini adalah semua karyawan pada PT. BPR Desa Sangeh Abiansemal Badung sebanyak 34 orang dan dalam menentukan sampel menggunakan metode jenuh yang berarti seluruh anggota populasi dilibatkan sebagai responden. Pengumpulan data primer dilakukan dengan metode kuisioner dan skala pengukuran yang digunakan adalah skala likert yang terdiri atas jawaban sangat tidak setuju diberi nilai 1 , jawaban tidak setuju diberi nilai 2, jawaban cukup setuju diberi nilai 3, jawaban setuju diberi nilai 4, dan jawaban sangat setuju diberi nilai 5. Untuk mendapatkan jawaban atas hipotesis yang telah diajukan maka teknik analisis data yang digunakan adalah regresi linear berganda untuk mengetahui pengaruh variabel bebas terhadap variabel terikat, serta uji t dan uji f.

\section{Hasil Dan Pembahasan}

\section{Uji Instrumen Penelitian}

Berdasarkan Tabel 1 diperoleh nilai koefisien korelasi > 0,3 dan cronbach's alpha > 0,60 yang berarti instrumen penelitian adalah valid dan reliabel.

Tabel 1. Hasil Uji Validitas dan Reliabilitas 


\begin{tabular}{|c|c|c|c|c|c|}
\hline \multirow[b]{2}{*}{ Variabel } & \multirow[b]{2}{*}{ Pernyataan } & \multicolumn{2}{|c|}{ Validitas } & \multicolumn{2}{|c|}{ Reliabilitas } \\
\hline & & $\begin{array}{c}\text { Koefisien } \\
\text { Korelasi }\end{array}$ & Ket. & $\begin{array}{c}\text { Cronbach's } \\
\text { Alpha }\end{array}$ & Ket. \\
\hline \multirow{10}{*}{$\begin{array}{c}\text { Budaya } \\
\text { Organisasi } \\
\left(\mathrm{X}_{1}\right)\end{array}$} & $\overline{X_{1.1}}$ & 0,756 & Valid & \multirow{10}{*}{0,919} & \multirow{10}{*}{ Reliabel } \\
\hline & $\mathrm{X}_{1.2}$ & 0,835 & Valid & & \\
\hline & $\mathrm{X}_{1.3}$ & 0,789 & Valid & & \\
\hline & $\mathrm{X}_{1.4}$ & 0,811 & Valid & & \\
\hline & $\mathrm{X}_{1.5}$ & 0,596 & Valid & & \\
\hline & $\mathrm{X}_{1.6}$ & 0,57 & Valid & & \\
\hline & $\mathrm{X}_{1.7}$ & 0,802 & Valid & & \\
\hline & $\mathrm{X}_{1.8}$ & 0,911 & Valid & & \\
\hline & $\mathrm{X}_{1.9}$ & 0,694 & Valid & & \\
\hline & $\mathrm{X}_{1.10}$ & 0,853 & Valid & & \\
\hline \multirow{14}{*}{$\begin{array}{l}\text { Lingkungan } \\
\text { Kerja }\left(\mathrm{X}_{2}\right)\end{array}$} & $\mathrm{X}_{2.1}$ & 0,7 & Valid & \multirow{14}{*}{0,947} & \multirow{14}{*}{ Reliabel } \\
\hline & $\mathrm{X}_{2.2}$ & 0,794 & Valid & & \\
\hline & $\mathrm{X}_{2.3}$ & 0,541 & Valid & & \\
\hline & $\mathrm{X}_{2.4}$ & 0,639 & Valid & & \\
\hline & $\mathrm{X}_{2.5}$ & 0,789 & Valid & & \\
\hline & $\mathrm{X}_{2.6}$ & 0,821 & Valid & & \\
\hline & $\mathrm{X}_{2.7}$ & 0,859 & Valid & & \\
\hline & $\mathrm{X}_{2.8}$ & 0,821 & Valid & & \\
\hline & $\mathrm{X}_{2.9}$ & 0,87 & Valid & & \\
\hline & $\mathrm{X}_{2.10}$ & 0,733 & Valid & & \\
\hline & $\mathrm{X}_{2.11}$ & 0,697 & Valid & & \\
\hline & $\mathrm{X}_{2.12}$ & 0,853 & Valid & & \\
\hline & $\mathrm{X}_{2.13}$ & 0,9 & Valid & & \\
\hline & $\mathrm{X}_{2.14}$ & 0,893 & Valid & & \\
\hline \multirow{10}{*}{$\begin{array}{l}\text { Kinerja } \\
\text { Karyawan } \\
\text { (Y) }\end{array}$} & $\mathrm{Y}_{1}$ & 0,772 & Valid & \multirow{10}{*}{0,902} & \multirow{10}{*}{ Reliabel } \\
\hline & $\mathrm{Y}_{2}$ & 0,901 & Valid & & \\
\hline & $Y_{3}$ & 0,78 & Valid & & \\
\hline & $\mathrm{Y}_{4}$ & 0,905 & Valid & & \\
\hline & $\mathrm{Y}_{5}$ & 0,741 & Valid & & \\
\hline & $\mathrm{Y}_{6}$ & 0,71 & Valid & & \\
\hline & $Y_{7}$ & 0,533 & Valid & & \\
\hline & $\mathrm{Y}_{8}$ & 0,774 & Valid & & \\
\hline & $\mathrm{Y}_{9}$ & 0,622 & Valid & & \\
\hline & $\mathrm{Y}_{10}$ & 0,805 & Valid & & \\
\hline
\end{tabular}

Sumber : data diolah, 2020

\section{Karakteristik Responden}

1. 23 responden $(67,6$ Persen) merupakan laki-laki dan 11 orang $(32,4$ Persen) adalah perempuan.

2. Responden usia $28-37$ tahun 15 orang (44,1 Persen) usia 18-27 tahun 9 orang $(26,5$ Persen), usia 38-47 tahun 7 orang (20,6 Persen) dan usia $>47$ tahun 3 orang (8,8 Persen).

3. Tingkat pendidikan responden jenjang SMA/K dan diploma 12 orang (35,3 Persen) dan tingkat pendidikan S1 sebanyak 10 orang (29,4 Persen).

4. Masa kerja 7-10 tahun sebanyak 12 orang (35,3 Persen), masa kerja 3-6 tahun yaitu 10 orang (29,4 Persen). Masa kerja $<3$ tahun dan $>10$ tahun 6 orang (17,6 Persen).

\section{Tabel 2. Karakteristik responden}




\begin{tabular}{clcc}
\hline Kriteria & \multicolumn{1}{c}{ Pilihan } & Jumlah (Orang) & Persentase (\%) \\
\hline \multirow{2}{*}{ Jenis } & Laki-laki & 23 & 67,6 \\
Kelamin & Perempuan & 11 & 32,4 \\
& Total & 34 & 100 \\
\hline \multirow{5}{*}{ Umur } & $18-27$ tahun & 9 & 26,5 \\
& 28-37 tahun & 15 & 44,1 \\
& 38-47 tahun & 7 & 20,6 \\
& $>47$ tahun & 3 & 8,8 \\
& Total & 34 & 100 \\
\hline \multirow{4}{*}{ Tingkat } & SMA/K & 12 & 35,3 \\
& Diploma & 12 & 35,3 \\
& S1 & 10 & 29,4 \\
& Total & 34 & 100 \\
\hline \multirow{5}{*}{ Masa Kerja } & 7-10 tahun & 6 & 17,6 \\
& $>10$ tahun & 10 & 29,4 \\
& T-6 tahun & 6 & 35,3 \\
& Total & 34 & 17,6 \\
\hline
\end{tabular}

Sumber : data diolah, 2020

\section{Deskripsi Variabel Penelitian}

Tabel 3. Deskripsi Variabel Budaya Organisasi

\begin{tabular}{|c|c|c|c|c|c|c|c|}
\hline \multirow{2}{*}{ Pernyataan } & \multicolumn{5}{|c|}{ Jawaban Responden } & \multirow{2}{*}{$\begin{array}{c}\text { Rata-Rata } \\
\text { Skor }\end{array}$} & \multirow{2}{*}{ Ket. } \\
\hline & STS & TS & CS & $\mathbf{S}$ & SS & & \\
\hline $\begin{array}{l}\text { Saya lebih mementingkan perusahaan } \\
\text { diatas kepentingan diri sendiri. }\end{array}$ & 0 & 0 & 8 & 13 & 13 & 4,15 & Baik \\
\hline $\begin{array}{l}\text { Setiap bekerja saya lebih mengutamakan } \\
\text { pelayanan umum dari pada kepentingan } \\
\text { kelompok. }\end{array}$ & 0 & 0 & 6 & 17 & 11 & 4,15 & Baik \\
\hline $\begin{array}{l}\text { Perusahaan menekankan pada aktivitas } \\
\text { kerja kelompok karyawan yang } \\
\text { terorganisasi. }\end{array}$ & 0 & 0 & 5 & 15 & 14 & 4,26 & $\begin{array}{c}\text { Sangat } \\
\text { Baik }\end{array}$ \\
\hline $\begin{array}{l}\text { Demi tercapainya tujuan perusahaan saya } \\
\text { harus bekerja sama dengan seluruh } \\
\text { anggota organisasi yang ada diperusahaan. }\end{array}$ & 0 & 0 & 6 & 16 & 12 & 4,18 & Baik \\
\hline $\begin{array}{l}\text { Untuk kepentingan dan kebutuhan orang } \\
\text { banyak dilakukan secara partisipasi } \\
\text { dengan mempertimbangkan mayoritas } \\
\text { karyawan. }\end{array}$ & 0 & 0 & 2 & 19 & 13 & 4,32 & $\begin{array}{c}\text { Sangat } \\
\text { Baik }\end{array}$ \\
\hline $\begin{array}{l}\text { Dalam mengambil kebijakan, perusahaan } \\
\text { melibatkan seluruh karyawannya. }\end{array}$ & 0 & 0 & 3 & 15 & 16 & 4,38 & $\begin{array}{c}\text { Sangat } \\
\text { Baik }\end{array}$ \\
\hline $\begin{array}{l}\text { Perusahaan telah melakukan } \\
\text { pengintegrasian antar fungsi atau unti- } \\
\text { unit kerja yang berbeda. }\end{array}$ & 0 & 0 & 7 & 12 & 15 & 4,24 & $\begin{array}{c}\text { Sangat } \\
\text { Baik }\end{array}$ \\
\hline $\begin{array}{l}\text { Perusahaan selalu mengoordinasikan } \\
\text { seluruh unit kerja yang berbeda agar } \\
\text { operasional berjalan dengan lancar. }\end{array}$ & 0 & 0 & 5 & 17 & 12 & 4,21 & $\begin{array}{c}\text { Sangat } \\
\text { Baik }\end{array}$ \\
\hline $\begin{array}{l}\text { Perilaku saya selalu dikontrol agar sesuai } \\
\text { dengan peraturan perusahaan. }\end{array}$ & 0 & 2 & 8 & 14 & 10 & 3,94 & Baik \\
\hline $\begin{array}{l}\text { Atasan selalu mengawasi karyawannya } \\
\text { dalam bekerja. }\end{array}$ & 0 & 0 & 6 & 18 & 10 & 4,12 & Baik \\
\hline & & & & & & 4,19 & Baik \\
\hline
\end{tabular}

Sumber : data diolah, 2020 
Berdasarkan Tabel 3 rata-rata skor dari variabel budaya organisasi yaitu sebesar 4,19 yang berarti baik karena berada pada kisaran 3,41-4,20. Rata-rata skor tertinggi ada pada pernyataan dalam mengambil kebijakan, perusahaan melibatkan seluruh karyawannya $\left(\mathrm{X}_{1.6}\right)$ yakni sebesar 4,38 sedangkan rata-rata skor terendah nampak pada pernyataan perilaku saya selalu dikontrol agar sesuai dengan peraturan perusahaan $\left(X_{1.9}\right)$ sebesar 3,94.

Tabel 4 menunjukkan bahwa rata-rata skor dari 14 pernyataan mengenai lingkungan kerja yaitu sebesar 4,15 yang berarti baik. Rata-rata skor tertinggi ada pada pernyataan cahaya atau penerangan sangat bermanfaat untuk kelancaran dalam bekerja $\left(\mathrm{X}_{2.1}\right)$ yakni sebesar 4,29 sedangkan rata-rata skor terendah nampak pada pernyataan perusahaan selalu memperhatikan suhu ruangan untuk kenyamanan karyawan bekerja $\left(\mathrm{X}_{2.3}\right)$ sebesar 3,85.

Tabel 4. Deskripsi Variabel Lingkungan Kerja

\begin{tabular}{|c|c|c|c|c|c|c|c|}
\hline \multirow{2}{*}{ Pernyataan } & \multicolumn{5}{|c|}{ Jawaban Responden } & \multirow{2}{*}{$\begin{array}{l}\text { Rata-Rata } \\
\text { Skor }\end{array}$} & \multirow{2}{*}{ Ket. } \\
\hline & STS & TS & $\mathbf{C S}$ & $\mathbf{S}$ & SS & & \\
\hline $\begin{array}{llll}\text { Cahaya atau penerangan } & \text { sangat } \\
\text { bermanfaat } & \text { untuk } & \text { kelancaran } & \text { dalam } \\
\text { bekerja. } & & & \\
& & \end{array}$ & 0 & 3 & 2 & 11 & 18 & 4,29 & $\begin{array}{c}\text { Sangat } \\
\text { Baik }\end{array}$ \\
\hline $\begin{array}{l}\text { Penerangan yang ada (sinar matahari dan } \\
\text { listrik) di ruang kerja telah sesuai dengan } \\
\text { kebutuhan. }\end{array}$ & 0 & 1 & 3 & 18 & 12 & 4,21 & $\begin{array}{c}\text { Sangat } \\
\text { Baik }\end{array}$ \\
\hline $\begin{array}{l}\text { Perusahaan selalu memperhatikan suhu } \\
\text { ruangan untuk kenyamanan karyawan } \\
\text { bekerja. }\end{array}$ & 0 & 6 & 4 & 13 & 11 & 3,85 & Baik \\
\hline $\begin{array}{l}\text { Pendingin ruangan yang disediakan sudah } \\
\text { sesuai dengan kebutuhan. }\end{array}$ & 0 & 1 & 6 & 11 & 16 & 4,24 & $\begin{array}{c}\text { Sangat } \\
\text { Baik }\end{array}$ \\
\hline $\begin{array}{l}\text { Bunyi yang bising dapat mengganggu } \\
\text { ketenangan karyawan dalam bekerja. }\end{array}$ & 0 & 2 & 3 & 14 & 15 & 4,24 & $\begin{array}{c}\text { Sangat } \\
\text { Baik }\end{array}$ \\
\hline $\begin{array}{l}\text { Area bekerja jauh dari gangguan yang } \\
\text { disebabkan oleh kebisingan. }\end{array}$ & 0 & 1 & 7 & 12 & 14 & 4,15 & Baik \\
\hline $\begin{array}{l}\text { Warna dinding pada ruangan kerja saya } \\
\text { sangat mendukung keadaan perasaan saya } \\
\text { dalam kerja. }\end{array}$ & 0 & 2 & 7 & 10 & 15 & 4,12 & Baik \\
\hline $\begin{array}{l}\text { Warna dinding pada ruangan kerja saya } \\
\text { masih terawat dan tidak pudar. }\end{array}$ & 0 & 1 & 7 & 15 & 11 & 4,06 & Baik \\
\hline $\begin{array}{l}\text { Jarak atau posisi duduk yg berdekatan } \\
\text { antara karyawan dangan karyawan lainnya } \\
\text { memudahkan untuk berkomunikasi dalam } \\
\text { bekerja. }\end{array}$ & 0 & 2 & 9 & 9 & 14 & 4,03 & Baik \\
\hline $\begin{array}{l}\text { Tata letak peralatan kerja seperti meja, } \\
\text { kursi dll tersusun rapi di ruang kerja }\end{array}$ & 0 & 0 & 9 & 16 & 9 & 4 & Baik \\
\hline $\begin{array}{l}\text { Kemampuan bekerja membuat saya } \\
\text { percaya diri dalam melakukan pekerjaan }\end{array}$ & 0 & 0 & 6 & 14 & 14 & 4,24 & $\begin{array}{c}\text { Sangat } \\
\text { Baik }\end{array}$ \\
\hline $\begin{array}{l}\text { Saya memiliki kemampuan yang dapat } \\
\text { mempercepat menyelesaikan pekerjaan. }\end{array}$ & 0 & 1 & 3 & 16 & 14 & 4,26 & $\begin{array}{c}\text { Sangat } \\
\text { Baik }\end{array}$ \\
\hline $\begin{array}{l}\text { Hubungan sesama rekan kerja sangat } \\
\text { harmonis. }\end{array}$ & 1 & 0 & 4 & 16 & 13 & 4,18 & Baik \\
\hline $\begin{array}{l}\text { Keharmonisan dengan rekan kerja } \\
\text { membuat saya lebih cepat dalam } \\
\text { menyelesaikan tugas }- \text { tugas perusahaan. }\end{array}$ & 0 & 1 & 4 & 16 & 13 & 4,21 & $\begin{array}{c}\text { Sangat } \\
\text { Baik }\end{array}$ \\
\hline & & & & & & 4,15 & Baik \\
\hline
\end{tabular}

Sumber : data diolah, 2020 
Tabel 5 menunjukkan bahwa rata-rata skor mengenai kinerja karyawan yaitu sebesar 4,15 yang berarti baik. Rata-rata skor tertinggi ada pada pernyataan saya mampu bekerja sama dengan rekan kerja dalam menyelesaikan pekerjaan ( $\mathrm{Y}_{9}$ ) yakni sebesar 4,32 sedangkan rata-rata skor terendah nampak pada pernyataan saya selalu hadir ke kantor sesuai dengan jadwal yang ditetapkan $\left(\mathrm{Y}_{7}\right)$ sebesar 3,76.

\section{Tabel 5. Deskripsi Variabel Kinerja karyawan}

\begin{tabular}{|c|c|c|c|c|c|c|c|}
\hline \multirow{2}{*}{ Pernyataan } & \multicolumn{5}{|c|}{ Jawaban Responden } & \multirow{2}{*}{$\begin{array}{l}\text { Rata-Rata } \\
\text { Skor }\end{array}$} & \multirow{2}{*}{ Ket. } \\
\hline & STS & TS & $\mathbf{C S}$ & $\mathbf{S}$ & SS & & \\
\hline $\begin{array}{l}\text { Saya mampu menyelesaikan } \\
\text { melebihi target yang } \\
\text { perusahan. }\end{array}$ & 0 & 0 & 4 & 20 & 10 & 4,18 & Baik \\
\hline $\begin{array}{l}\text { Pekerjaan yang saya lakukan sudah } \\
\text { mencapai target } \text { yang ditentukan } \\
\text { perusahaan. }\end{array}$ & 0 & 0 & 5 & 19 & 10 & 4,15 & Baik \\
\hline $\begin{array}{l}\text { Saya selalu bekerja berdasarkan ketepatan, } \\
\text { ketelitian, keterampilan dan kebersihan. }\end{array}$ & 0 & 0 & 4 & 19 & 11 & 4,21 & $\begin{array}{c}\text { Sangat } \\
\text { Baik }\end{array}$ \\
\hline Saya teliti dalam menyelesaikan pekerjaan. & 0 & 0 & 3 & 20 & 11 & 4,24 & $\begin{array}{c}\text { Sangat } \\
\text { Baik }\end{array}$ \\
\hline $\begin{array}{l}\text { Saya dapat menyelesaikan pekerjaan sesuai } \\
\text { dengan waktu yang telah ditetapkan } \\
\text { perusahaan. }\end{array}$ & 0 & 2 & 3 & 15 & 14 & 4,21 & $\begin{array}{c}\text { Sangat } \\
\text { Baik }\end{array}$ \\
\hline Saya tidak pernah menunda pekerjaan. & 0 & 0 & 4 & 19 & 11 & 4,21 & $\begin{array}{c}\text { Sangat } \\
\text { Baik }\end{array}$ \\
\hline $\begin{array}{l}\text { Saya selalu hadir ke kantor sesuai dengan } \\
\text { jadwal yang ditetapkan. }\end{array}$ & 0 & 1 & 5 & 18 & 10 & 3,76 & Baik \\
\hline Saya tiba di tempat kerja selalu tepat waktu. & 0 & 5 & 8 & 11 & 10 & 4,09 & $\mathrm{Ba}$ \\
\hline $\begin{array}{l}\text { Saya mampu bekerja sama dengan rekan } \\
\text { kerja dalam menyelesaikan pekerjaan. }\end{array}$ & 0 & 1 & 3 & 14 & 16 & 4,32 & $\begin{array}{l}\text { Sangat } \\
\text { Baik }\end{array}$ \\
\hline $\begin{array}{l}\text { Saya lebih banyak bekerja sama dalam } \\
\text { menyelesaikan pekerjaan dari pada bekerja } \\
\text { individu. }\end{array}$ & 0 & 0 & 5 & 19 & 10 & 4,15 & Baik \\
\hline & & & & & & 4,15 & Baik \\
\hline
\end{tabular}

Sumber : data diolah, 2020

\section{Uji Asumsi Klasik}

Hasil Tabel 6 menunjukan nilai Asymp. Sig. (2-tailed) adalah 0,804 lebih besar dari 0,05. Dengan demikian dapat dikatakan bahwa variabel tersebut berdistribusi normal.

Tabel 6. Hasil Uji Normalitas

One-Sample Kolmogorov-Smirnov Test

\begin{tabular}{llr}
\hline & & $\begin{array}{c}\text { Unstandardized } \\
\text { Residual }\end{array}$ \\
\hline $\mathrm{N}$ & Mean & 34 \\
Normal Parameters ${ }^{\mathrm{a}, \mathrm{b}}$ & Std. Deviation & 0 \\
& Absolute & 0,30243047 \\
Most Extreme Differences & Positive & 0,11 \\
& Negative & 0,11 \\
Kolmogorov-Smirnov Z & & $-0,068$ \\
Asymp. Sig. (2-tailed) & & 0,642 \\
\hline
\end{tabular}

Sumber : data diolah, 2020 
Hasil pada Tabel 7 menunjukan nilai tolerance variabel bebas $>0,10$. Nilai varians inflation factor (VIF) VIF $<10$ artinya tidak terjadi gejala multikolinearitas dalam model.

Tabel 7. Hasil Uji Multikolinearitas

\begin{tabular}{|c|c|c|c|}
\hline \multirow{2}{*}{\multicolumn{2}{|c|}{ Model }} & \multicolumn{2}{|c|}{ Collinearity Statistics } \\
\hline & & Tolerance & VIF \\
\hline \multirow{3}{*}{1} & (Constant) & & \\
\hline & Budaya Organisasi $\left(\mathrm{X}_{1}\right)$ & 0,828 & 1,208 \\
\hline & Lingkungan Kerja $\left(\mathrm{X}_{2}\right)$ & 0,828 & 1,208 \\
\hline
\end{tabular}

Sumber : data diolah, 2020

Hasil uji Glejser pada Tabel 8 diperoleh nilai signifikansi semua variabel bebas bernilai Sig. > 0,05. Hal ini berarti model regresi tersebut tidak mengandung gejala heteroskedastisitas.

Tabel 8. Hasil Uji Heteroskedastisitas

\begin{tabular}{llrrrrr}
\hline \multirow{2}{*}{ Model } & \multicolumn{2}{c}{$\begin{array}{c}\text { Unstandardized } \\
\text { Coefficients }\end{array}$} & $\begin{array}{c}\text { Standardized } \\
\text { Coefficients }\end{array}$ & \multirow{2}{*}{ t } & \multirow{2}{*}{ Sig. } \\
\cline { 2 - 4 } & \multicolumn{1}{c}{ B } & Std. Error & Beta & & \\
\hline \multirow{2}{*}{1} & (Constant) & 0,204 & 0,295 & & 0,692 & 0,494 \\
& Budaya Organisasi $\left(\mathrm{X}_{1}\right)$ & 0,054 & 0,07 & 0,151 & 0,775 & 0,444 \\
& Lingkungan Kerja $\left(\mathrm{X}_{2}\right)$ & $-0,05$ & 0,058 & $-0,167$ & $-0,858$ & 0,398 \\
\hline
\end{tabular}

Sumber : data diolah, 2020

\section{Analisis Koefisien Determinasi}

Determinasi sebesar 82,6 persen, artinya budaya organisasi $\left(\mathrm{X}_{1}\right)$ dan lingkungan kerja $\left(\mathrm{X}_{2}\right)$ mampu menjelaskan kinerja karyawan (Y) sebesar 82,6 persen. Sisanya sebesar 17,4 persen (100 persen - 82,6 persen) tidak diteliti dalam penelitian ini seperti motivasi, kompensasi, kepuasan yang dapat mempengaruhi kinerja karyawan.

Tabel 9. Hasil Analisis Koefisien Determinasi Model Summary

\begin{tabular}{rlrrrr}
\hline Model & $\mathrm{R}$ & R Square & $\begin{array}{c}\text { Adjusted R } \\
\text { Square }\end{array}$ & $\begin{array}{c}\text { Std. Error of the } \\
\text { Estimate }\end{array}$ \\
\hline 1 & $.826^{\mathrm{a}}$ & .681 & .661 & .31203 \\
\hline
\end{tabular}

Sumber : data diolah, 2020

\section{Analisis Regresi Linear Berganda}

Dari hasil Tabel 10 diperoleh nilai $\mathrm{a}=0,477$, nilai $\mathrm{b}_{1}=0,478$, nilai $\mathrm{b}_{2}=0,402$, maka persamaan regresi berganda menjadi: $Y=0,477+0,478 X_{1}+0,402 X_{2}$

\section{Tabel 10. Hasil Analisis Regresi Linear Berganda}

\begin{tabular}{|c|c|c|c|c|c|}
\hline \multirow[t]{2}{*}{ Model } & \multicolumn{2}{|c|}{$\begin{array}{c}\text { Unstandardized } \\
\text { Coefficients }\end{array}$} & \multirow{2}{*}{$\begin{array}{c}\begin{array}{c}\text { Standardized } \\
\text { Coefficients }\end{array} \\
\text { Beta }\end{array}$} & \multirow[t]{2}{*}{$\mathrm{t}$} & \multirow[t]{2}{*}{ Sig. } \\
\hline & $\mathrm{B}$ & Std. Error & & & \\
\hline (Constant) & 0,477 & 0,46 & & 1,037 & 0,308 \\
\hline Budaya Organisasi $\left(\mathrm{X}_{1}\right)$ & 0,478 & 0,109 & 0,487 & 4,369 & 0 \\
\hline Lingkungan Kerja $\left(\mathrm{X}_{2}\right)$ & 0,402 & 0,09 & 0,495 & 4,441 & 0 \\
\hline
\end{tabular}

Dependent Variable : Kinerja Karyawan

Sumber : data diolah, 2020 
Uji signifikansi parsial (uji t) digunakan untuk secara parsial (individu) kontribusi yang ditimbulkan dari masing-masing variabel bebas yaitu budaya organisasi dan lingkungan kerja terhadap kinerja karyawan. Hasil Uji t dapat dilihat pada Tabel 10.

1. Pengaruh Budaya Organisasi Terhadap Kinerja Karyawan Pada PT. BPR Desa Sangeh Abiansemal Badung

Pengaruh budaya organisasi terhadap kinerja karyawan, menunjukkan bahwa budaya organisasi berpengaruh positif dan signifikan terhadap kinerja karyawan. Hal ini dapat dilihat dari hasil koefisien regresi 0,478 (positif) dengan nilai $t_{\text {hitung }}(4,369)>t_{\text {tabel }}(2,039)$ dan tingkat signifikansi sebesar 0,000 lebih kecil dari 0,05 yang berarti $\mathrm{H}_{1}$ diterima.

Hasil tersebut membuktikan bahwa peran budaya organisasi dapat meningkatkan kinerja karyawan. Jika budaya organisasi yang dijalankan baik akan meningkatkan kinerja karyawan, tetapi jika budaya organisasi yang dijalankan buruk akan mengakibatkan kinerja karyawan menurun.

Hasil penelitian ini searah dengan kajian yang dilakukan oleh Pratiwi (2014) dengan judul "Pengaruh Lingkungan Kerja dan Budaya Organisasi terhadap Kinerja Karyawan PT. Bank Riau Kepri Capem Duri”. Hasil penelitiannya menunjukan bahwa budaya organisasi berpengaruh terhadap kinerja karyawan.

2. Pengaruh Lingkungan Kerja Terhadap Kinerja Karyawan Pada PT. BPR Desa Sangeh Abiansemal Badung

Pengaruh lingkungan kerja terhadap kinerja karyawan, menunjukkan bahwa lingkungan kerja berpengaruh positif dan signifikan terhadap kinerja karyawan. Hal ini dapat dilihat dari hasil koefisien regresi sebesar 0,402 (positif) dengan nilai $t_{\text {hitung }}(4,441)>t_{\text {tabel }}$ (2,039) dan tingkat signifikansi sebesar 0,000 lebih kecil dari 0,05 yang berarti $\mathrm{H}_{2}$ diterima.

Hasil tersebut membuktikan bahwa peran lingkungan kerja dapat meningkatkan kinerja karyawan. Lingkungan kerja yang nyaman dan bersih akan dapat meningkatkan semangat kerja karyawan sehingga kinerja yang dihasilkan maksimal. Sebaliknya, lingkungan kerja yang buruk akan mengakibatkan karyawan tidak bersemangat dalam bekerja.

Hasil penelitian ini searah dengan kajian yang dilakukan oleh Pratiwi (2014) dengan judul "Pengaruh Lingkungan Kerja dan Budaya Organisasi terhadap Kinerja Karyawan PT. Bank Riau Kepri Capem Duri”. Hasil penelitiannya menunjukan bahwa lingkungan kerja berpengaruh terhadap kinerja karyawan. 


\section{Uji Signifikansi Simultan (Uji F)}

Pengaruh budaya organisasi dan lingkungan kerja terhadap kinerja karyawan, menunjukkan bahwa budaya organisasi dan lingkungan kerja berpengaruh signifikan terhadap kinerja karyawan. Hal ini dapat dilihat dari hasil analisis data Uji F dengan nilai $F_{\text {hitung }}(33,160)>F_{\text {tabel }}(3,30)$ yang berarti $\mathrm{H}_{3}$ diterima. Hasil ini menunjukkan budaya organisasi dan lingkungan kerja secara simultan berpengaruh signifikan terhadap kinerja. Hal tersebut membuktikan bahwa peran budaya organisasi dan lingkungan kerja secara bersama-sama dapat meningkatkan kinerja karyawan.

Hasil penelitian ini searah dengan kajian yang dilakukan oleh Pratiwi (2014) dengan judul "Pengaruh Lingkungan Kerja dan Budaya Organisasi terhadap Kinerja Karyawan PT. Bank Riau Kepri Capem Duri”. hasil penelitiannya menunjukan bahwa budaya organisasi dan lingkungan kerja secara silmutan berpengaruh signifikan terhadap kinerja karyawan.

\section{Tabel 11. Hasil Uji F} ANOVA ${ }^{\mathrm{a}}$

\begin{tabular}{|c|c|c|c|c|c|c|}
\hline \multicolumn{2}{|c|}{ Model } & $\begin{array}{c}\text { Sum of } \\
\text { Squares }\end{array}$ & df & $\begin{array}{c}\text { Mean } \\
\text { Square }\end{array}$ & $\mathrm{F}$ & Sig. \\
\hline \multirow{3}{*}{1} & Regression & 6.457 & 2 & 3.229 & 33.160 & $.000^{\mathrm{b}}$ \\
\hline & Residual & 3.018 & 31 & .097 & & \\
\hline & Total & 9.476 & 33 & & & \\
\hline
\end{tabular}

Sumber : data diolah, 2020

\section{Penutup}

\section{Simpulan}

Berdasarkan hasil analisis dan pembahasan mengenai pengaruh budaya organisasi dan lingkungan kerja terhadap kinerja karyawan pada PT. BPR Desa Sangeh Abiansemal Badung dapat disimpulkan sebagai berikut :

1. Berdasarkan hasil uji statistik $t$ didapat nilai $t_{\text {hitung }}=4,369>t_{\text {tabel }}=2,039$ dan signifikansi sebesar $0,000<0,05$. Dapat disimpulkan bahwa budaya organisasi berpengaruh positif dan signifikan (nyata) terhadap kinerja karyawan pada PT. BPR Desa Sangeh Abiansemal Badung.

2. Berdasarkan hasil uji statistik $t$ didapat nilai $t_{\text {hitung }}=4,441>t_{\text {tabel }}=2,039$ dan signifikansi sebesar $0,000<0,05$. Dapat disimpulkan bahwa lingkungan kerja berpengaruh positif dan signifikan (nyata) terhadap kinerja karyawan pada PT. BPR Desa Sangeh Abiansemal Badung. 
3. Berdasarkan hasil uji statistik $F$ didapat nilai $F_{\text {hitung }}=33,160>F_{\text {tabel }}=3,30$. Dapat disimpulkan budaya organisasi dan lingkungan kerja berpengaruh signifikan (nyata) terhadap kinerja karyawan pada PT. BPR Desa Sangeh Abiansemal Badung.

\section{Saran}

Berdasarkan kesimpulan hasil penelitian yang telah diuraikan diatas selanjutnya ditemukan hasil implikasi sebagai berikut:

1. Indikator kontrol (control) dengan pernyataan perilaku saya selalu dikontrol agar sesuai dengan peraturan perusahaan pada variabel budaya organisasi mendapatkan skor terendah dari tanggapan responden, maka disarankan kepada manajemen perusahaan agar selalu mengontrol perilaku karyawannya dalam bekerja sehingga karyawan bekerja sesuai dengan peraturan yang telah ditetapkan.

2. Indikator suhu udara dengan pernyataan perusahaan selalu memperhatikan suhu ruangan untuk kenyamanan karyawan bekerja pada variabel lingkungan kerja mendapatkan skor terendah dari tanggapan responden, maka disarankan kepada manajemen perusahaan agar memperhatikan suhu ruangan untuk kenyamanan karyawan bekerja dan memasang AC dibeberapa ruangan sehingga membuat udara tidak pengap.

3. Indikator kehadiran dengan pernyataan saya selalu hadir ke kantor sesuai dengan jadwal yang ditetapkan pada variabel kinerja karyawan mendapatkan skor terendah dari tanggapan responden, maka disarankan kepada manajemen perusahaan agar lebih tegas dalam mendisiplinkan karyawan sehingga tidak ada karyawan yang absen melebihi toleransi yang ditetapkan perusahaan.

4. Bagi peneliti selanjutnya, agar mengambil variabel lain yang mempengaruhi kinerja karyawan, seperti: promosi jabatan, prestasi kerja, stres kerja, dll. dengan jumlah sampel yang lebih banyak dan juga tempat penelitian yang berbeda.

\section{Referensi}

Ajala, Emmanuel Majekodunmi. 2012. The Influence Of Workplace Environment On Workers'Welfare, Performance and Productivity. An Journal of the African Educational Research Network.

Bank Indonesia. 1998. UU No.10 tahun 1998, Tentang Perubahan Terhadap UU No. 7 tahun 1992, Jakarta.

Basri, A. F. M., dan Rivai,V.2005. Performance appraisal. Jakarta: PT Raja. Grafindo Persada.

Budianto dan Amelia Kartini. 2015. Pengaruh Lingkungan Kerja Terhadap Kinerja Pegawai pada PT Perusahaan Gas Negara (PERSERO) Tbk SBU Distributor Wilayah 1 Jakarta. Jurnal Ilmiah Manajemen Universitas Pamulang.

Cahyono, S. 2012. Membangun budaya keselamatan pasien dalam praktik kedokteran, Yogyakarta. 
Djuremi., Hasiholan dan Minarsih. 2016. Pengaruh Lingkungan Kerja, Budaya Organisasi, dan Kepemimpinan terhadap Kinerja Pegawai pada Dinas Pasar Kota Semarang. Jurnal Manajemen Universitas Pandanaran.

Fahmi, Irham. 2010. Manajemen Resiko. Bandung: Alfabeta.

Ghozali, Imam. 2016. Aplikasi Analisis Multivariete Dengan Program IBM SPSS 23 (Edisi 8). Cetakan ke VIII. Semarang : Badan Penerbit Universitas Diponegoro.

Hadari Nawawi. 2005. Penelitian Terapan. Yogyakarta: Gajah Mada University Press.

Hariandja, Marihot Tua Efendi. 2007. Manajemen Sumber Daya Manusia, Jakarta: PT. Gramedia Widiasarana Indonesia.

Istianto, Bambang. 2006. Manajemen Pemerintahan Dalam Persepektif Pelayanan Publik. Jakarta : Mitra Wacana Media.

Isyandi, B. 2004. Manajemen Sumber Daya Manusia Dalam Perspektif Global. Pekanbaru, Unri Press.

Kasmir. 2008. Analisis Laporan Keuangan, Rajawali Pers, Jakarta.

Kotler, Philip. 2000. Marketing Management. Edisi Milenium, Prentice Hall Intl, Inc New Jersey.

Mangkunegara, A.A Anwar Prabu. 2005. Manajemen Sumber daya Manusia Perusahaan. Bandung : PT Remaja Rosdakarya.

Mathis, R.L. \& J.H. Jackson. 2006. Human Resource Management: Manajemen Sumber Daya Manusia. Terjemahan Dian Angelia. Jakarta: Salemba Empat.

McShane, Steven L. \& Von Glinow, Mary Ann. 2008. Organizational Behavior. Fourth Edition. McGRAW-Hill International, United States of America.

Misrania, Yulia. 2016. Pengaruh Kepuasan, Disiplin Kerja, Lingkungan Kerja dan Motivasi terhadap Kinerja Karyawan (Studi Kasus Pada Perusahaan Asuransi Bumiputera 1912 Cabang Syariah Palembang). Jurnal Ekonomia STIE Lembah Dempo.

Nitisemito. 2006. Manajemen Personalia, Edisi kedua, Ghalia Indonesia.

Nuraini,T. 2013. Manajemen Sumber Daya Manusia, Yayasan Aini Syam: Pekanbaru.

Pratiwi, Amelia., Nuryanti dan Iwan N. Daulay. 2014. Pengaruh Lingkungan Kerja dan Budaya Organisasi terhadap Kinerja Karyawan PT. Bank Riau Kepri Capem Duri. Jurnal Ekonomi Universitas Riau.

Prawirosentono, Suyadi.1999. Manajemen sumber Daya Manusia (Kebijakan Kinerja Karyawan), Kiat membangun Organisasi Kompetitif menjelang Perdagangan Bebas Dunia, Edisi Pertama. Yogyakarta;BPFE.

Priansa, Donni Juni, dan Agus Garnida. 2013. Manajemen Pekantoran. Alfabeta. Bandung. Robbins, S. 2008. Perilaku Organisasi, Jilid I dan II, alih Bahasa : Hadyana Pujaatmaja. Jakarta: Prenhallindo.

Robbins, Stephen P. dan Coulter, Mary. 2010. Manajemen Edisi Kesepuluh. Jakarta: penerbit Erlangga.

Robbins dan Judge. 2011. Perilaku Organisasi, Edisi 12, Salemba Empat

Russel dan Bernardin. 1993. Human resources Management, New York: Prentice Hall.

Sedarmayanti. 2011a. Manajemen Sumber Daya Manusia, Reformasi Birokrasi danManajemen Pegawai Negeri Sipil (cetakan kelima). Bandung : PT RefikaAditama. Maju.

2014b. Sumber Daya Manusia dan Produktivitas Kerja. Jakarta: Mandar

2015c. Manajemen Sumber Daya Manusia. Bandung: Refika Aditama.

Shahzad, Khurram. 2011. Impact of work-life conflict on perceived employee performance: evidence from Pakistan. European Journal of Economics, Finance and Administrative Sciences. 
Siagian, Sondang P. 2009. Manajemen Sumber Daya Manusia, Edisi.1, Cetakan.17 Jakarta, Bumi Aksara.

Simamora, Henry. 2015. Manajemen Sumber Daya Manusia.Yogyakarta: STIEY.

Simanjuntak, Payaman J. 2003. Produktivitas Kerja Pengertian dan Ruang Lingkupnya, Prisma, Jakarta.

Simanjuntak. 2011. Manajemen Evaluasi Kinerja. Edisi 3. Jakarta. Fakutas UI.

Sugiyono. 2012a. Metode Penelitian Kuantitatif Kualitatif dan R\&D. Bandung:Alfabeta.

----------. 2014b. Metode Penelitian Pendidikan Pendekatan Kuantitatif, Kualitatif, dan R\&D. Bandung: Alfabeta.

Sutrisno, Edy. 2014. Manajemen Sumber Daya Manusia. Cetak Ke Enam. Pranada Media Group, Jakarta.

Timpe. 1992. Kinerja. Jakarta: PT.Gramedia.

Wuradji. 2009. The educational leadership, kepemimpinan transformasional. Yogyakarta:Gama Media. 